\title{
Chemoprophylaxis of Dirofilaria immitis (Leidy 1856) infection at a high challenge environment
}

\author{
Norma Vollmer Labarthe ${ }^{1,2}$ (D), Liliane Maria Valentim Willi ${ }^{3^{*}}$, Jonimar Pereira Paiva ${ }^{4}$, \\ Marcia Gonçalves Nobre de Miranda ${ }^{5}$, Karen Zoreck ${ }^{6}$ and Flavya Mendes de Almeida ${ }^{1}$
}

\begin{abstract}
Background: The frequency of canine heartworm infection in the state of Rio de Janeiro, Brazil was high before chemoprophylactic treatment was available, with one of the highest rates of infection (52.5\%) found among dogs living on the eastern shore of the state. Following the launch of a chemoprophylactic product, the rate of infection gradually decreased, and new infections were rarely reported. After 2005, outbreaks reported at the eastern shore as well as for new infections in other areas of high infection frequency were considered to possibly be related to reduced efficacy of macrocyclic lactones. Therefore, this study aimed to evaluate the efficacy of topical heartworm preventatives from different drug families at the high challenge area of the state of Rio de Janeiro.
\end{abstract}

Methods: A total of 46 dogs, including animals negative for Dirofilaria immitis microfilariae and antigen (Snap 4 Dx, IDEXX Laboratories, USA) at the initial screening were randomly allocated to two monthly treatment groups. Dogs in one group received topical moxidectin + imidacloprid and dogs in the other group received topical selamectin for eight consecutive months. Blood samples were obtained for microfilariae and antigen detection until the eleventh month after the first treatment. Dogs becoming microfilaremic or antigenemic on or before day 180 were considered to be infected prior to the first dose and were excluded from the study.

Results: A total of 29 dogs completed the study, including 14 treated with moxidectin + imidacloprid and 15 treated with selamectin. No dogs treated with moxidectin + imidacloprid (0/14) became infected during the treatment period, whereas four dogs of the selamectin group (4/15) became infected.

Conclusion: Topical moxidectin + imidacloprid is $100 \%$ effective in preventing D. immitis infections in dogs living in a high challenge natural environment.

Keywords: Canine heartworm, Macrocyclic lactones, Preventive medication

\section{Background}

Dirofilaria immitis (Leidy, 1856) Raillet \& Henry, 1911 is a mosquito-borne parasite species present worldwide and is frequently found infecting Brazilian dogs [1]. As in other areas of the world, its transmission depends on the presence of microfilaremic dogs, competent mosquito vectors, and susceptible dogs [2, 3].

\footnotetext{
* Correspondence: liliwillimonteiro@hotmail.com

${ }^{3}$ Doutoranda do Programa de Pós-Graduação em Medicina Veterinária, Faculdade de Medicina Veterinária, Universidade Federal Fluminense, Rua Vital Brazil 64, Santa Rosa, CEP 24230-340 Niterói, RJ, Brazil

Full list of author information is available at the end of the article
}

Before the year of 1992, when the first chemoprophylactic treatment was launched in Brazil, reported canine heartworm infection frequency at the state of Rio de Janeiro ranged from $14 \%$ to $17 \%[4,5]$. During those years (1988-1990), at the eastern shore of the state, the frequency was as high as $52.5 \%$ [5]. During the following years (2000-2001), after the first chemoprophylactic product was launched, a downward trend in heartworm infection occurred in Brazil [6,7], and new infections were rarely reported.

In 2005, following the availability of chemoprophylactic heartworm treatments, the first heartworm outbreak in the state was identified in the area of the 
eastern shore, with $53 \%$ of the dogs found to be infected [8]. Following the first outbreak, many other infections were reported, and lack of efficacy of macrocyclic lactones in preventing infections was suspected in high infection frequency areas of the state [9]. An update of the 2005 outbreak area six years later showed that infection frequency was even higher (80\%) [10, 11], which, along with local veterinarians reports that dogs on chemoprophylaxis were becoming infected (personal communication), suggests the presence of less susceptible populations of D. immitis at the site. Therefore, the aim of this study was to evaluate the efficacy of topical heartworm preventatives from different drug families at the high challenge area of the state of Rio de Janeiro.

\section{Methods}

In order to identify as many as possible $D$. immitis microfilariae and antigen negative dogs living at the high challenge area, all dog owners were invited to participate of the study. According to the approval of the ethical committee of the Universidade Federal Fluminense (233) and after obtaining owner consent, blood samples were obtained from 80 chemoprophylaxis naïve dogs (32 under 12 months old; 19 from 1 to 2 years old and 29 over 2 years) for detection of microfilariae using Knott's modified test (Newton \& Wright, 1956) and ELISA test (Snap 4 Dx IDEXX Laboratories, USA).

After screening, 46 out of the 49 dogs with negative test results on both tests $(26 / 46,56.5 \%$ less than 1 year of age) were included in the study and randomly sorted in two groups; dogs in one group received topical moxidectin + imidacloprid at 2.5 to $6.25 \mathrm{mg}$ moxidectin $/ \mathrm{kg} /$ month (23 dogs); dogs in the second group received topical selamectin at 6 to $12 \mathrm{mg} / \mathrm{kg} /$ month (23 dogs). Every monthly treatment was administered by the veterinarians participating in the study after weighing the dogs and adjusting the dose if necessary. Dogs were treated on days $0,30,60,90,120,150,180$ and 210
( \pm 5 days), and blood samples were obtained on days -2 , $30,90,150,180,210,240,270$, and 300 ( \pm 5 days) for microfilariae detection. On days $-2,90,150,180$, and 300 , plasma samples were tested for detection of antigens by the same ELISA test used for the initial screening. Plasma from all microfilaremic samples obtained on days 30, 210, 240, or 270 was also tested for antigens (Fig. 1).

Dogs becoming microfilaremic or antigenemic on day 180 or before were considered to be infected prior to the first chemoprophylactic dose. Those dogs and any other inadvertently treated with macrocyclic lactones by the owners were excluded from the study.

Detection of infected dogs during the study were evaluated for significance of differences between the treatment groups by chi square or Fisher's exact tests.

\section{Results}

The initial screening of 80 dogs detected 31 positive for microfilariae and/or D. immitis antigen (38.8\%). Among the 46 dogs included, 14 of the moxidectin + imidacloprid group and 15 of the selamectin group completed the study. On day 180, one of the selamectin dogs became microfilaremic and became antigen positive later. Therefore, this dog was considered to have been previously infected before the study was initiated. The number of dogs in the selamectin group that became infected during the treatment period (4/15) was higher than the moxidectin + imidacloprid treated group (0/14) $\left(\chi^{2}=2.38 ; \mathrm{p}=0.057\right)$ (Table 1$)$. Among the four selamectin-treated dogs that became infected during the study, three tested positive for microfilariae and antigen and one was antigen-positive but was amicrofilaremic. Therefore the efficacy of the selamectin treatment was $73.3 \%$ and the efficacy of the moxidectin + imidacloprid treatment was $100 \%$.

\section{Discussion}

Because dogs had to be free of detectable microfilariae and antigens to be included in the study and the challenge at the study site was known as very high, young

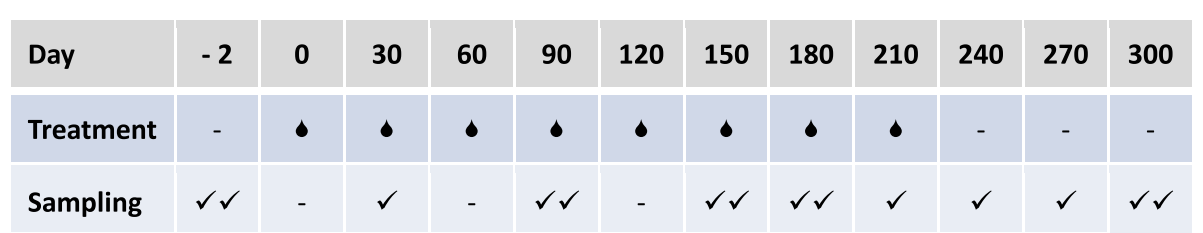

Figure 1 Timeline of canine treatments and blood sampling

(৬) Treatment with topical moxidectin + imidacloprid at 2.5 to $6.25 \mathrm{mg}$ moxidectin $/ \mathrm{kg}$ or topical selamectin at 6 to $12 \mathrm{mg} / \mathrm{kg}$ $(\checkmark)$ Blood sampling of dogs for microfilariae detection

$(\checkmark \checkmark)$ Blood sampling of dogs for microfilariae and antigen detection

Fig. 1 Timeline of canine treatments and blood sampling. 
Table 1 Number and percentage of dogs receiving monthly treatment with topical moxidectin + imidacloprid or selamectin treatment positive for microfilariae or antigen of Dirofilaria immitis at different study intervals from day 30 (after first treatment) up to day 300 after the first treatment

\begin{tabular}{llll}
\hline & Day 30 to $150^{\mathrm{a}}$ & Day $180^{\mathrm{b}}$ & Day 270 to 300 \\
Monthly treatment & No. pos./total & No. pos./total & No. pos./total \\
\hline Moxidectin + imidacloprid & $3 / 23(13.0 \%)$ & $0 / 18(0 \%)$ & $0 / 14^{\mathrm{a}}(0 \%)$ \\
Selamectin & $6 / 23(26.1 \%)$ & $1 / 20(5.0 \%)$ & $4 / 15^{\mathrm{b}}(26.7 \%)$ \\
\hline
\end{tabular}

${ }^{a}$ Considered to be infected before the first treatment

${ }^{\mathrm{b}}$ Possibly infected before the first treatment

Different superscript letters in columns are significantly different $\left(x^{2}=2.38 ; p=0.057\right)$

dogs were privileged. Even so, the percent of positive test results was high (38.75\%), confirming previous results [11] and demonstrating how intense the challenge was. Therefore, the severe life threatening cardiopulmonary condition the infection determines, the risk treatment imposes to the dogs and the zoonotic potential of the infection highlights the definite need for chemoprophylaxis in order to control transmission. Minimizing the number of infected dogs acting as reservoirs of the parasite is pivotal to reduce the chance of infective blood meals for mosquitoes and to reduce the occurrence of $D$. immitis in vectors, dogs and humans. Besides the direct impact upon D. immitis transmission, the use of topical moxidectin/imidacloprid or topical selamectin provides reliable control against other major endo and ectoparasites.

The main reasons for macrocyclic lactones treatment failures which may impair analysis of lack of efficacy or resistance are known to be underdosing and owners' noncompliance [12-15], which were carefully controlled in the present study. Therefore, the results obtained ruled out major indirect reasons for lack of efficacy at a high natural challenge area were the occurrence of resistant populations or lack of efficacy can't be disregarded.

Topical moxidectin + imidacloprid was more efficacious $(100 \%)$ than topical selamectin $(73.3 \%)$ in preventing $D$. immitis infection, as it had been shown before when the resistant strains MP3 or JYD-34 were used as models for evaluation of efficacy [13, 16, 17]. Furthermore, it should be considered that since macrocyclic lactones may stunt $D$. immitis development for nine months when administered accordingly to recommendations (John Wilson McCall - personal communication), it is possible to assume that infection of the selamectin dogs occurred prior to the first treatment dose and that selamectin treatment was ineffective in eliminating the infection although stunted worm development.

Therefore, it is possible to infer that topical moxidectin + imidacloprid, when consistently administered to dogs on a monthly schedule, is highly effective in preventing heartworm patent infections in treated dogs living in extreme challenge situations, such as those found in the coastal lowland of the eastern state of Rio de Janeiro, Brazil $[8,9,11,18]$, the Mississippi delta in the United States [12], and others.

\section{Conclusions}

Topical moxidectin + imidacloprid was $100 \%$ effective for $D$. immitis prevention in dogs living in a high challenge natural environment therefore at those environments should be the chemoprophylaxis of choice. These results suggest that experimental studies should be conducted to elucidate the stunting effect of different macrocyclic lactones consistent treatment.

\section{Competing interests}

Norma Labarthe is a consultant for Bayer Animal Health, Idexx Laboratories, and Zoetis in Brazil.

Flavya-Mendes-de-Almeida is a consultant for Bayer Animal Health and Idexx Laboratories.

Jonimar Paiva is a consultant for Zoetis in Brazil.

Karen Zoreck is a current employee of Bayer Animal Health in Brazil.

Liliane Willi and Marcia Nobre de Miranda have no competing interests.

\section{Authors' contributions}

NVL conceived of the study and participated in coordination of the study, the acquisition of data, interpretation of results, and helped to draft the manuscript. FMA participated in the study coordination, acquisition of data, laboratory analysis and helped to draft the manuscript. LMVW participated in the acquisition of data, interpretation of results, and helped to draft the manuscript. JPP participated in the acquisition of data and performed the statistical analysis. MGNM participated in the acquisition of data and laboratory analysis. KZ participated in the study design. All authors read and approved the final manuscript.

\section{Acknowledgements}

The authors acknowledge Carolina Haje, Daniel Marques, Daniel Paiva, Thiago Gomes, Marcela Machado, Monique Paiva for assistance in the acquisition of data. The authors thank Kathleen Newcomb, Nathalie, VA, USA for editorial assistance in the preparation of this manuscript.

\section{Funding}

Funding for this study and the publication of the results was provided by Bayer Animal Health.

\section{Author details}

${ }^{1}$ Programa de Pós-Graduação em Medicina Veterinária, Faculdade de Veterinária, Universidade Federal Fluminense, Rua Vital Brazil 64, Santa Rosa, CEP 24230-340 Niterói, RJ, Brazil. ${ }^{2}$ Programa Institucional Biodiversidade e Saúde, Fundação Oswaldo Cruz, Av. Brasil 4036, Manguinhos, CEP 21040-361 Rio de Janeiro, RJ, Brazil. ${ }^{3}$ Doutoranda do Programa de Pós-Graduação em 
Medicina Veterinária, Faculdade de Medicina Veterinária, Universidade Federal Fluminense, Rua Vital Brazil 64, Santa Rosa, CEP 24230-340 Niterói, RJ, Brazil. ${ }^{4}$ Departamento de Medicina e Cirurgia Veterinária, Instituto de Veterinária, Universidade Federal Rural do Rio de Janeiro, BR-465, Km 7, CEP 23890-000 Seropédica, RJ, Brazil. ${ }^{5}$ Médica Veterinária Vet Ypiranga, Rua Ypiranga 107, Laranjeiras, CEP 22231-120 Rio de Janeiro, RJ, Brazil. 'Bayer S.A., Bayer Technology Services, Av. das Américas, 500, Downtown Bloco 11, Loja 108, 26640-100 Rio de Janeiro, RJ, Brazil.

Received: 13 May 2015 Accepted: 3 October 2015

Published online: 12 October 2015

\section{References}

1. Labarthe N, Paiva JP, Reifur L, Mendes-de-Almeida F, Merlo A, Pinto CC, et al. Updated canine infection rates for Dirofilaria immitis in areas of Brazil previously identified as having a high incidence of heartworm-infected dogs. Parasit Vectors. 2014;7:493.

2. Walters LL. Risk factors for heartworm infection in northern California. In: Soll MD, Knight DH, editors. Proceedings of the Heartworm Symposium'95. Batavia, IL: American Heartworm Society; 1995. p. 5-26.

3. Wang D, Bowman DD, Brown HE, Harrington LC, Kaufman PE, McKay T, et al. Factors influencing U.S. canine heartworm (Dirofilaria immitis) prevalence. Parasit Vectors. 2014;7:264.

4. Guerrero J, Vezzoni A, Ducos de Lahitte J, Bussieras J, Rojo FA, Ortega LM, et al. Distribution of Dirofilaria immitis in selected areas of Europe and South America. In: Otto GH, editor. Proceedings of the Heartworm Symposium '89. Washington DC: American Heartworm Society; 1989. p. 13-8.

5. Labarthe NV, Almosny NR, Guerrero J, Duque-Araújo AM. Description of the occurrence of canine dirofilariasis in the state of Rio de Janeiro, Brazil. Mem Inst Oswaldo Cruz. 1997;92:47-51.

6. Costa RC, Couto-Lima A, Serrão ML, Labarthe N. An update survey of the prevalence of canine dirofilariasis in a focus area of the city of Rio de Janeiro, Brazil. Rev Bras Parasitol Vet. 2004;13:23-8.

7. Labarthe N, Campos Pereira MC, Barbarini O, Mckee W, Coimbra CA, et al. Serologic Prevalence of Dirofilaria immitis, Ehrlichia canis and Borrelia burgdorferi Infections in Brazil. Vet Ther. 2003;4:67-73.

8. Bendas AJR, Paiva JP, Doria MI, Mendes-de-Almeida F, Branco AS, Silvano DRB, et al. Ocorrência de Dirofilaria immitis no entorno de um caso diagnosticado na Zona Sul do Rio de Janeiro/RJ, Brasil. Acta Sci Vet. 2007;35:678-79.

9. Labarthe NV, Bendas, AJR, Paiva JP, Branco AS, Belmonte D, Mendes-deAlmeida F, et al. Recrudescimento das infecções por Dirofilaria immitis (Leidy, 1856) na região oceanic de Niterói, RJ. In Annals of XLVII Congresso da Sociedade Brasileira de Medicina Tropical Natal RN, Brasil; 2011:1313

10. Mendes-de-Almeida F, Willi L, Paiva JP, Miranda M, Marques D, Ramos C, et al. Circulação de Dirofilaria immitis no estado do Rio de Janeiro: revisita ao foco da região dos lagos. Acta Sci Vet. 2012;40:65.

11. Willi L, Mendes-de-Almeida F, Willi L, Paiva JP, Marques D, Ramos C, et al. Dirofilaria immitis em paisagens distintas no estado do Rio de Janeiro. In Annals of XVII Congresso Brasileiro de Parasitologia Veterinária São Luís MA, Brasil; 2012:133

12. Bowman DD, Atkins CE. Heartworm biology, treatment and control. Vet Clin North Anim: Small Anim Pract. 2009;39:1127-58.

13. Bowman DD. Heartworms, macrocyclic lactones, and the specter of resistance to prevention in the United States (Review). Parasit Vectors. 2012;5:138.

14. Companion Animal Parasite Council. 2013. Current advice on parasite control: heartworm - canine heartworm. Available at http://www.capcvet.org. Accessed 15 Oct 2014

15. Atkins CE, Murray MJ, Olavessen LJ, Burton KW, Marshall JW, Brooks CC. Heartworm "lack of effectiveness" claims in the Mississipi delta: computerized analysis of owner compliance 2004-2011. Vet Parasitol. 2014:206:106-13.

16. Blagburn BL, Dillon AR, Arther RG, Butler JM, Newton JC. Comparative efficacy of four commercially available heartworm preventive products against the MP3 laboratory strain of Dirofilaria immitis. Vet Parasitol. 2011;176:189-94.
17. Blagburn BL, Carmichael J, Kaminsky R, Schenker R, Kaplan R, Moorhead A, et al. Resistance and heartworm preventives: historical perspectives and overview of research (abstract). American Heartworm Society; 2013:21

18. Bendas, AJR, Paiva JP, Branco AS, Belmonte DR, Mendes-de-Almeida, F Guerrero J, et al. Back to Rio! The return of heartworm infections in dogs (abstract). 13th Triennial State of the Heartworm Symposium, Memphis. 2010

\section{Submit your next manuscript to BioMed Central and take full advantage of:}

- Convenient online submission

- Thorough peer review

- No space constraints or color figure charges

- Immediate publication on acceptance

- Inclusion in PubMed, CAS, Scopus and Google Scholar

- Research which is freely available for redistribution 